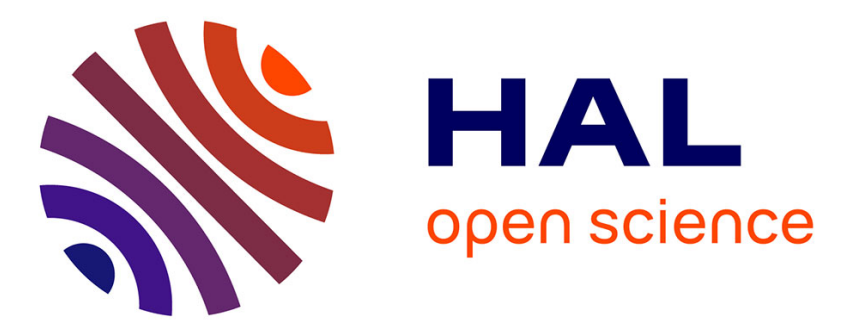

\title{
Relationships between processing conditions and mechanical properties of PA12 tubes
}

Jean-Marc Haudin, Aurélien Carin, Michel Vincent, Nicolas Amouroux, Gaëlle Bellet, Fabrice Montezin

\section{- To cite this version:}

Jean-Marc Haudin, Aurélien Carin, Michel Vincent, Nicolas Amouroux, Gaëlle Bellet, et al.. Relationships between processing conditions and mechanical properties of PA12 tubes. Proceedings of the 12th ESAFORM Conference on Material Forming, Apr 2009, Enschede, France. pp.Pages 861-864, 10.1007/s12289-009-0606-6 . hal-00509432

\section{HAL Id: hal-00509432}

https://hal-mines-paristech.archives-ouvertes.fr/hal-00509432

Submitted on 12 Aug 2010

HAL is a multi-disciplinary open access archive for the deposit and dissemination of scientific research documents, whether they are published or not. The documents may come from teaching and research institutions in France or abroad, or from public or private research centers.
L'archive ouverte pluridisciplinaire HAL, est destinée au dépôt et à la diffusion de documents scientifiques de niveau recherche, publiés ou non, émanant des établissements d'enseignement et de recherche français ou étrangers, des laboratoires publics ou privés. 


\title{
RELATIONSHIPS BETWEEN PROCESSING CONDITIONS AND MECHANICAL PROPERTIES OF PA12 TUBES
}

\author{
J.M. Haudin ${ }^{\text {1* }}$ A. Carin ${ }^{1}$, M. Vincent ${ }^{1}$, N. Amouroux ${ }^{2}$, G. Bellet ${ }^{2}$, F. Montezin ${ }^{2}$ \\ ${ }^{1}$ Mines ParisTech, CEMEF - Centre de Mise en Forme des Matériaux, CNRS UMR 7635, BP 207, \\ 1 rue Claude Daunesse, 06904 Sophia Antipolis, France \\ ${ }^{2}$ Arkema, Cerdato, 27470 Serquigny, France
}

\begin{abstract}
In polyamide 12 (PA12) tube extrusion, calibration is the key step of the process that affects the subsequent mechanical properties. In previous work it has been shown that according to the calibration conditions, a very oriented skin layer may be created, which has been correlated to an important decrease of elongation at break. In this paper, we present new results showing a good correlation between molecular orientation and fracture toughness, as evaluated by the EWF (Essential Work of Fracture) approach. They concern notched specimens and confirm the results obtained in classical tensile testing. EWF is very sensitive to processing conditions, and especially to induced orientation: it decreases from the external to the inner regions of the tube, and increases with skin orientation.
\end{abstract}

KEYWORDS: polyamide 12, tube extrusion, calibration, molecular orientation, essential work of fracture.

\section{INTRODUCTION}

In polyamide 12 (PA12) tube extrusion, calibration is crucial for the major final properties such as elongation at break. In external calibration, the extruded tube is pulled through a cylindrical calibrator located in a water tank under vacuum. The calibration step may generate a highly oriented zone in the external layers of the tube, as shown by birefringence measurements. In previous work, a correlation has been established between the tube elongation at break and skin birefringence [1], a higher orientation inducing a lower elongation. We also developed a thermomechanical model of the process in order to provide a physical interpretation of the development of orientation in the outer layers of the tube [2]. The results clearly show that the axial stresses concentrate in the first solidified layers, inducing plastic deformation, hence molecular orientation and low elongation at break.

In this paper, we present new results showing a good correlation between molecular orientation and fracture toughness, as evaluated by the EWF (Essential Work of Fracture) approach. They concern notched specimens and confirm the results obtained in classical tensile testing. It appears that EWF is very sensitive to processing conditions, and especially to induced orientation.

\section{THEORETICAL BACKGROUND}

The EWF (Essential Work of Fracture) method is a very popular approach to evaluate the fracture toughness of ductile polymers. It uses notched specimens with different notch sizes. According to Broberg [3], the plastic region at the crack tip can be divided into a Fracture Plastic Zone (FPZ) where the fracture process takes place, and an Outer Process Zone (OPZ) subjected to large plastic strains.

The total work of fracture $W_{f}$ can be decomposed into two components:

$$
W_{f}=W_{e}+W_{p}
$$

$W_{e}$ is the essential work of fracture associated to the FPZ and $W_{p}$ is the non-essential work of fracture corresponding to plastic deformation in the OPZ. Equation (1) is usually rewritten as:

$$
w_{f}=\frac{W_{f}}{l t}=w_{e}+\beta w_{p} l
$$

where $t$ is the thickness, $l$ is the ligament length, $w_{e}$ is the specific essential work of fracture (in $\mathrm{kJ} / \mathrm{m}^{2}$ ), $w_{p}$ is the specific non-essential work of fracture (in $\mathrm{MJ} / \mathrm{m}^{3}$ ) and $\beta$ is the shape factor. If for specimens with different ligament lengths, $w_{f}$ is plotted against $l$, a straight line is obtained with $w_{e}$ as ordinate and $\beta w_{p}$ as slope.

\footnotetext{
* Corresponding author: Mines ParisTech, CEMEF, BP 207, 06904 Sophia Antipolis, France. Phone: + 33 (0) 4939575 03, fax: + 33 (0) 4923897 52, email address: Jean-Marc.Haudin@mines-paristech.fr
} 


\section{EXPERIMENTAL}

\subsection{MATERIAL AND EXTRUSION CONDITIONS}

A PA12 grade for extrusion and blow molding was used: $\mathrm{M}_{\mathrm{n}}=25700 \mathrm{~g} / \mathrm{mol}$ and $\mathrm{M}_{\mathrm{w}}=7700 \mathrm{~g} / \mathrm{mol}$.

Experiments were carried out on an Arkema experimental extrusion line producing $8 \mathrm{~mm}$ diameter PA12 tubes. The polymer was extruded at $227^{\circ} \mathrm{C}$, and pulled through a cylindrical calibrator made of brass and located in a water tank under vacuum $[1,2]$. Level of vacuum $(\Delta \mathrm{P})$ is adjustable and allows tube external diameter to be fitted. At the entrance, water fills an annular channel, which supplies water between tube and calibrator. The sizing sleeve length was $70 \mathrm{~mm}$, and the calibrator inner diameter was $9 \mathrm{~mm}$.

The present study concerned multilayered tubes consisting of five layers: $\mathrm{PA} / \mathrm{PE} / \mathrm{PA} / \mathrm{PE} / \mathrm{PA}$. The thickness of each PA layer was about $100 \mu \mathrm{m}$, and that of each PE layer about $350 \mu \mathrm{m}$. As a consequence, the total thickness of the tube was about $1 \mathrm{~mm}$. Two levels of vacuum were applied: 100 and 225 mbar.

\subsection{MECHANICAL TESTING}

Using a Zwick machine, tensile tests were carried out on notched specimens with the DDENT (Deep Double Edge-Notched Tension) geometry, for different ligament lengths. These specimens, which were prepared from PA layers extracted from tubes, are presented in Table 1. They were drawn at $2 \mathrm{~mm} \mathrm{~min}^{-1}$ and at $25^{\circ} \mathrm{C}$.

Table 1: Samples analyzed by the EWF method

\begin{tabular}{cc}
\hline Reference & $\Delta \mathrm{P}$ and analyzed PA layer \\
\hline $101 \mathrm{~A}$ & $100 \mathrm{mbar}-$ external \\
\hline $102 \mathrm{~A}$ & $225 \mathrm{mbar}-$ external \\
\hline $101 \mathrm{C}$ & $100 \mathrm{mbar}-$ intermediate \\
\hline $101 \mathrm{E}$ & $100 \mathrm{mbar}-$ internal \\
\hline
\end{tabular}

This mechanical characterization concerned both the longitudinal $(\mathrm{z})$ and the tangential $(\theta)$ directions of the tube. The dimensions of the specimens drawn along $\mathrm{z}$ were: length $\mathrm{L}$ (along $\mathrm{z}$ ) $=100 \mathrm{~mm}$, width $\mathrm{W}$ (along $\theta$ ) $=20 \mathrm{~mm}$ and $2<$ ligament length $l$ (along $\theta$ ) $<8 \mathrm{~mm}$ (dimensions 1). For tensile tests along $\theta$, other dimensions are necessary: $\mathrm{L}$ (along $\theta$ ) $=10 \mathrm{~mm}, \mathrm{~W}$ (along z) $=20 \mathrm{~mm}$ and $2<l$ (along $\mathrm{z}$ ) $<8 \mathrm{~mm}$ (dimensions 2). For comparison, specimens with dimensions 2 were also tested along $\mathrm{z}$.

\subsection{MOLECULAR ORIENTATION}

Light microscopy (Leica DMRX microscope) was used to characterize the global orientation by birefringence measurements.

\section{RESULTS}

Figure 1 presents typical tensile curves obtained for a given specimen and different ligament lengths. The treatment of these curves using Equation (2) makes it possible to determine $w_{e}$ and $\beta w_{p}$ (Figure 2). The values obtained for all the specimens analyzed are displayed in Table 2: $w_{e}$ varies between 12.8 and $66.7 \mathrm{~kJ} / \mathrm{m}^{2}$ and $\beta w_{p}$ ranges from 7.1 to $16.2 \mathrm{MJ} / \mathrm{m}^{3}$. These results are in agreement with literature data. For instance, Yamakawa et al. found $36.94 \mathrm{~kJ} / \mathrm{m}^{2}$ and $16.77 \mathrm{MJ} / \mathrm{m}^{3}$ for polyamide 6.

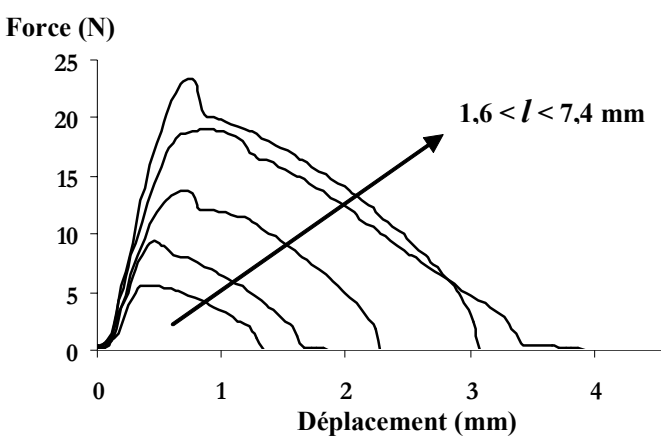

Figure 1: Force-displacement curve for sample 101C drawn along $\mathrm{z} ; \mathrm{I}=1.6,1.8,2.8,3.6,3.9,4.7,5.5,7.1,7.4$ $\mathrm{mm}$

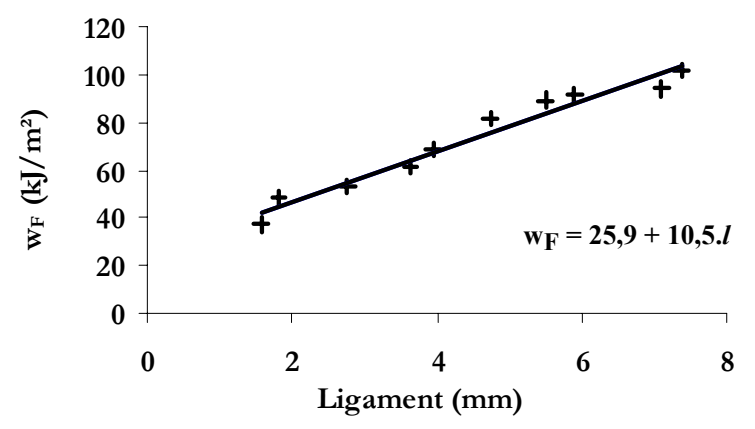

Figure 2: $w_{f} v s$. ligament length for sample 101C drawn along $\mathrm{z}$

\section{DISCUSSION}

\subsection{COMPARISON BETWEEN SKIN AND CORE}

The results of tests $101 \mathrm{~A} \mathrm{z}, 101 \mathrm{C} \mathrm{z}$ and $101 \mathrm{E} \mathrm{z}$ make it possible to compare the mechanical behaviour of the skin (external layer) and the core (intermediate and internal layers) regions.

$w_{e}$ is the greatest in the external layer, which can be attributed to the high molecular orientation developed in this region. In previous work on monolayer tubes [1], the identification of the extinction lines observed on polished sections revealed high birefringence values at the skin, decreasing rapidly from the external surface to the inside of the tube. At the external surface, they were 
always greater than 0.018 , while they were lower than 0.01 beyond the 100 external microns. Observation of thin microtomed cuts confirmed a great orientation of the external skin. Thickness of this skin varied from $11.6 \mu \mathrm{m}$ to $23.3 \mu \mathrm{m}$ and its birefringence was between 0.018 and 0.033. This skin birefringence was correlated to the elongation at break of the tubes: it appeared that elongation at break significantly decreased as the skin orientation increased. The same birefringence levels were obtained here: 0.018 at the external surface and less than 0.05 for the intermediate and internal layers.

Table 2: Specific essential and non-essential works of fracture

Dimensions 1

\begin{tabular}{cccc}
\hline Reference & $\begin{array}{c}\text { Tension } \\
\text { along }\end{array}$ & $\begin{array}{c}w_{e} \\
\left(\mathrm{~kJ} / \mathrm{m}^{2}\right)\end{array}$ & $\begin{array}{c}\beta w_{p} \\
\left(\mathrm{MJ} / \mathrm{m}^{3}\right)\end{array}$ \\
\hline $101 \mathrm{~A} \mathrm{z}$ & $\mathrm{z}$ & 47.2 & 16.2 \\
\hline $101 \mathrm{C} \mathrm{z}$ & $\mathrm{z}$ & 25.9 & 10.5 \\
\hline $101 \mathrm{E} \mathrm{z}$ & $\mathrm{z}$ & 12.8 & 11.6 \\
\hline $102 \mathrm{~A} \mathrm{z}$ & $\mathrm{z}$ & 66.7 & 9.6 \\
\hline
\end{tabular}

Dimensions 2

\begin{tabular}{cccc}
\hline Reference & $\begin{array}{c}\text { Tension } \\
\text { along }\end{array}$ & $\begin{array}{c}w_{e} \\
\left(\mathrm{~kJ} / \mathrm{m}^{2}\right)\end{array}$ & $\begin{array}{c}\beta w_{p} \\
\left(\mathrm{MJ} / \mathrm{m}^{3}\right)\end{array}$ \\
\hline 101A $\theta$ & $\theta$ & 17.6 & 7.6 \\
\hline $102 \mathrm{~A} \mathrm{z}$ & $\mathrm{z}$ & 53.4 & 13.6 \\
\hline $102 \mathrm{~A} \theta$ & $\theta$ & 29.2 & 7.1 \\
\hline
\end{tabular}

Conversely, the orientation level cannot explain the difference between the intermediate and internal layers. Crystallinity might play a role, since we observed in additional experiments that the internal layers were not fully crystallized during the process [5].

$\beta w_{p}$ also decreases significantly from the skin to the core regions. Nevertheless, in this case the interpretation is more difficult, since the shape factor $\beta$ may considerably vary with the sample morphology.

\subsection{CALIBRATION CONDITIONS}

The influence of the calibration conditions can be pointed out by comparing tests $101 \mathrm{~A} \mathrm{z}$ and $102 \mathrm{~A} \mathrm{z}$. When the level of vacuum increases from 100 to 225 mbar, the birefringence at the external surface increases from 0.018 to 0.033 and consequently, $w_{e}$ increases from 47.2 to $66.7 \mathrm{~kJ} / \mathrm{m}^{2}$. The same trend is not observed for $\beta w_{p}$.

\subsection{MECHANICAL ANISOTROPY}

The mechanical anisotropy in the tubes can be characterized thanks to tensile tests along $\theta$. Along the chain direction the material is stiffer, and both $w_{e}$ and $\beta w_{p}$ are greater than in the perpendicular direction. Also note that the use of smaller dimensions lead to a significant decrease of $w_{e}\left(-13.3 \mathrm{~kJ} / \mathrm{m}^{2}\right)$.

\subsection{INITIATION VERSUS PROPAGATION}

According to Karger-Kocsis et al. [6], $w_{e}$ can be splitted into a component due to initiation and a component due to propagation of fracture (Table 3 ). The same trends are observed for these components as for the total esssential work of fracture: the higher the orientation, the greater these components. Furthermore, it appears that the most important part of the essential work is employed to propagate fracture.

Table 3: Initiation and propagation components of the specific essential work of fracture

\begin{tabular}{ccc}
\hline Reference & $\begin{array}{c}w_{e} \text { initiation } \\
\left(\mathrm{kJ} / \mathrm{m}^{2}\right)\end{array}$ & $\begin{array}{c}w_{e} \text { propagation } \\
\left(\mathrm{kJ} / \mathrm{m}^{2}\right)\end{array}$ \\
\hline $101 \mathrm{~A} \mathrm{z}$ & 16.6 & 30.6 \\
\hline $101 \mathrm{C} \mathrm{z}$ & 8.9 & 17.0 \\
\hline $101 \mathrm{E} \mathrm{z}$ & 2.3 & 10.4 \\
\hline $102 \mathrm{~A} \mathrm{z}$ & 28.4 & 38.3 \\
\hline
\end{tabular}

\section{CONCLUSIONS}

The local mechanical behaviour of PA12 tubes can be approached through the use of multilayered tubes. The fracture toughness of these tubes has been characterized by the EWF method. EWF is very sensitive to processing conditions, and especially to induced orientation. In correlation with orientation evolution, it has been clearly shown that:

- it decreases from the external to the inner regions of the tube,

- it increases with skin orientation.

Accordingly, molecular orientation significantly increases the essential work of fracture These results confirm those obtained in classical tensile testing and are also in agreement with the literature [7].

\section{REFERENCES}

[1] Carin A., Haudin J. M., Vincent M., Monasse B., Bellet G., Amouroux, N.: External calibration in PA12 tube extrusion. II. Relations between molecular orientation, tensile properties and polymer drawing during calibration. Intern. Polym. Proc., 20:305-311, 2005.

[2] Haudin J. M., Carin A., Parant O. Guyomard A., Vincent M., Peiti C., Montezin F.: A mechanical model for stress development in PA12 tube extrusion. Application to structure development. Intern. Polym. Proc., 23:55-64, 2008.

[3] Broberg K. B.: Critical review of some theories in fracture mechanics. Intern. J. Fracture Mech., 4(1):11-18, 1968.

[4] Yamakawa R. S., Razzino C. A., Correa C. A., Hage Jr. E.: Influence of notching and molding conditions 
on determination of EWF parameters in polyamide 6. Polymer Testing, 23:195-202, 2004.

[5] Carin A.: Etude expérimentale et modélisation thermomécanique de l'étape de calibration dans le procédé d'extrusion de tubes en polyamide 12. $\mathrm{PhD}$ Thesis, Ecole des Mines de Paris, 2005.

[6] Karger-Kocsis J., Czigany T., Moskala E. J.:
Deformation rate dependence of the essential and non-essential work of fracture parameters in amorphous copolyester. Polymer, 39:3939-3944, 1998.

[7] Paton, C. A., Hashemi, S.: Plane-stress essential work of ductile fracture of polycarbonate. J. Mater. Sci., 27:2279-2290, 1992. 